\title{
The Influence of Differences in Values between Chinese and Western Cultures on Communication Modes
}

\section{Honggang Han}

Weinan Normal University, Weinan, Shaanxi, 714000

\begin{abstract}
Keywords: Chinese culture, Western culture, Intercultural communication, Values, Differences, Communication modes, Influence
\end{abstract}

\begin{abstract}
In recent years, the international political, economic and cultural exchanges have become increasingly frequent and the cooperation and exchanges between the peoples of various countries in the world have also been increasing. However, in intercultural communication, communicators often cause language integration and cultural integration due to their different cultural backgrounds Such as short-circuit social activities, so understand the basic cultural differences between China and the West and the impact of intercultural communication is particularly important. This article discusses the influence of the differences of western values on the communicative modes.
\end{abstract}

\section{Introduction}

Intercultural communication refers to the process in which communicators with different cultural backgrounds use the same language or nonverbal language to communicate thoughts, feelings and information in a given communication context. In the process of cultural exchanges between China and the West, there is no obstacle to the use of language. Chinese and English played a very important role in the culture of China and the West. However, there is a huge gap in behavior, thinking, interpersonal relationships and ways of doing things The difference.

\section{For the concept of time}

Westerners always uphold the "time is life" doctrine of time, for all do not abide by the time, a waste of time abhorrence. Their arrangements for time can be described as "锠 baht will be more," when the schedule is lined up after the day, will not be easily changed, whether it is about or about to be covenant, must be in advance appointment, there is no rash visit caused by the owner Discomfort, when they start to do something, often in strict accordance with the timetable, meticulous strict implementation, within the scheduled time, has not completed the work at hand, it will immediately stop, according to the schedule On the arrangement of the contents of the matter, into the next task, the stop must stop, the end must also end. In the Western life, once promised, it means to bet on their own credibility, who would not want to be that unprofitable, unprincipled person, it will not appear clearly agreed afternoon 4:00 to meet, but did not appear on time, appeared in the conversation by other events or people to disturb the situation, once agreed, during that time, the time should belong only to both the subject and the guest. Westerners' strictness and awe of time have reached the level of a paranoid Chinese can not understand. Westerners call it one-way time.

Compared with the Westerners, such as cherish the time, planning, pay attention to scheduling, and once their conflict with the original plan, it will be dismissed from the temporary arrangements for work; and Chinese people are very different treatment time, usually think of the West to arrange work too rigid, inflexible, unreasonable. This attitude toward time can subtly and potentially affect the relationship between us and the people around us, leaving people of different cultural backgrounds often confused. For example, a Chinese professor who wants to leave the United States invited a professor from the United States to have dinner together as a goodbye. He did not expect the American professor to make a face-saving refusal and explained that he had arranged. Such examples naturally lead us to think that Americans are too unfeeling. In fact, it is precisely 
because of the difference in time concept that this view has been produced. In China, it is often the case that people meet better, but they interrupt the conversation with guests or temporarily walk away when they pick up a phone call. They often go out of their way at the last minute to miss the bus and miss The train situation. Time is fair to everyone, but in China we tend to use humankind in the face of immutable things, such as helping and facilitating ourselves with contingent queues on the basis of urgency, and most of the people Will also choose to agree, rather than opposed to late, unruly people waste and squeeze their own time.

\section{For praise.}

Chinese people have always respected doing things "think twice before", consider the issue must be comprehensive, polite, courteous, humble humility, not ambitious. Communication for the sake of each other, choose the appropriate and euphemistic speech expression point of view. In the western countries that emphasize personal supremacy, however, they have shown directness, decisiveness and ambition. Americans have been educated since childhood to be confident, independent, neat and tidy, lack of self-confidence or offensive people is difficult to be socially accepted. For example, if someone praises: "Your job is doing well!" The reaction of the Westerners must be: "Thank you very much." The reaction of the Chinese is: "Where! Where!" Westerners want their personality and ability to get Social recognition, and the Chinese even though they are very sympathetic to the praise of others, but verbally afraid to disclose, for fear of being crowned with hat. This is actually caused by the differences between Chinese and Western cultures.

\section{For cooperation and ways of doing things.}

The differences between the outlook on life and the values in China and the West are mainly manifested in collectivism and individualism. As a result of their overall priority and harmony above thought, Chinese people are even more in favor of collectivism. Everyone relies on and obeys not only the collective but also the security and care of the collective. Many Chinese proverbs embody this value orientation: "gunning a bird of prey," "fear of being afraid of a famous pig," "rash in the early rash," and so on. People are reluctant to express different opinions, maintain harmony and avoid disagreements. They must consider the opinions of others before doing anything, demand that individual interests obey the collective rejuvenation, and even sacrifice their own freedom to protect the interests of the community. It seems incredible to Westerners. Westerners pay attention to independence and autonomy, emphasizing the antagonism and incoordination between individuals and collectives. They pay more attention to the realization of personal existence and individual values, regard personal interests as paramount, advocate independent thinking, independently judge and rely on their own ability to realize personal interests, stressing that " Self ", showing strong affirmation and highlighting self color in intercultural communication. This affirmed self-conscious ideology is manifested in its actions by daring to flaunt and highlight itself, to dare to say it and to dare to express itself Strong self-struggle and self-fulfilling enterprising spirit. To Americans, the Chinese are not accustomed to making their personal opinions public because the Chinese can not tell the difference between "right" and "right". Westerners make personal opinions as "discuss matters" and "not right things." Both parties in the dispute clearly understand that they will gain fame and fortune, and they may still be good friends after the meeting. In addition, the notion of a private affair in China is not strong and it is mainly a trace of the traditional group life that leaves behind each other. What is regarded as "privacy" in the eyes of Westerners is a concrete manifestation of concern for others in the eyes of Chinese. Such as asking someone's age, occupation, income, marital status, weight, etc. are all normal. To a large extent, all the taboos in the West about privacy such as age, marital status, income and religious beliefs are due to their deep-rooted individualism and individualism. 


\section{For interpersonal relationships and patterns.}

Westerners still permeate deep independent and free thoughts in interpersonal communication. Their historical background and economic environment have created their utmost value for freedom and independence. They are adventurous, advocating equality and democracy. In the early American films, many of the themes are about the pursuit and exploration of "freedom." Therefore, among the Westerners, more is advocating freedom and equality, the most criticized in the United States system, nothing more than racial discrimination, but the blacks never stopped searching for freedom and equality. In the process of interaction with people, Westerners have always maintained their autonomy. They are only subject to their own tendency to desire. They never readily accept orders from others or impose their will. They hope that they will be respected and will respect others accordingly. When dealing with things, Westerners in general uphold the official attitude of the public, not to consider the human face and face. When communicating with others, you will also deal with the situation more positively, rather than giving vent to your dissatisfaction or love.

On the contrary, the Chinese are even more perceptual in their interpersonal relationships. This is probably why the Chinese write so many romantic stories. Their feelings are plentiful and plentiful, allowing the Chinese to express themselves more freely. "For the poor A thousand miles, a higher level, "so clearly in Chinese poetry, reflected in English, the translation is often the word is not intended, which is also the Chinese people implicitly and gracefully created, and correspondingly, in Chinese of the interpersonal relationships, more emphasis is often not correct or not the event, the first reaction is: whether this thing makes me uncomfortable, and then will consider its fairness and rationality. In the process of dealing with problems, they often have no distinction between the public and the private. They confuse the personal emotional relationship with the public relations, and they often use the human feelings as a means of dealing. In addition, the Asians prefer to adopt the communication mode of other people's orientation. That is, when words are helpful to each other, they are sometimes imposed on each other regardless of their willingness to show their sincerity and the other side will not feel unhappy. Influenced by Confucianism, they emphasize benevolence in interpersonal communication. When dealing with each other, they should consider "long-aged and orderly" and "friends have faith." In their relations with their neighbors, they also emphasize mutual assistance, mutual dependence and support. The phrase "neighboring gold, neighboring silver, and adjacent friendship and winning gold and silver" truly reflects the principle of friendship that Chinese people follow when they get along with others.

\section{For education.}

In Western culture, parents often develop their children more independently and have their own living ability. Both parents and children are equal. At home, parents and children can directly call each other's names without regard to other parents. Advise their children to do more than to interfere in ways that help their children make choices. The final choice should only be in the hands of the parties involved. Choosing a school, choosing a spouse, choosing a career, choosing a life, Complete autonomously.

In the Chinese culture, although the father is a subculture belonging to the feudal culture, filial piety has been handed down all the time. Parents also feel that they have a great mission. From the day when they gave birth to their children, their lives are bound firmly with their children. Together, to help children choose food, to help children dress, feed their children, choose their children to schools, choose teachers, choose friends, in the name of love to interfere with the child's emotional life, and other children grew up, Marriage, the constant selection of blind date for the child and the object of marriage, but also sad children's bride wealth, dowry, buy a home for their children's property, it seems that everything is for the child to consider, but in fact the child's right to choose firmly Tightly clutched in his own hand will not let go, which also resulted in the emergence of Chinese-style "giant baby", the Chinese and Western cultures in the process of exchange and collision, there will often be misunderstood by both parties are difficult to understand . In recent 
years, with the improvement of China's overall national strength and the fact that more Chinese choose to go out and look at the outside world, it also brings back the idea of independence and freedom in Western culture. More Chinese youth choose to take charge of their own lives, and Parents and friendly conversation, so that parents feel comfortable enjoying their own old age life at the same time, from a different perspective on contemporary youth lifestyle changes.

In intercultural communication, this cultural difference always affects our communication tendency, communication style and communication strategy. In actual cross-cultural exchanges, we must treat all kinds of different issues in a realistic and pragmatic manner, respect each other's own cultural practices, understand each other's basic cultural differences and learn from each other, handle each other's differences in a tolerant spirit and seek common grounds while reserving differences Exchanges and cooperation among different cultural backgrounds, enhancing our sensitivity in intercultural communication and enhancing our communication strategy so that communication can be more effective and decent.

\section{References}

[1] On the relationship between Chinese and Western time viewpoints and the cultivation of intercultural communicative competence in Chinese international teaching, Ren Le - "Jiannan Literature: Classics Reading" - 2013 - Cited by: 1. Source: Wanfang / Love academic

[2] Analysis of the Intercultural Communication Barrier of the Movie "The 13 Girls of Jinling" The Cultural Conflict Prominent in the Case of the "13 Days of Jinling" Written by Western Media, for example, Ke Wei - "Movie Review" - 2012 - Quotations: 5

[3] Analysis of the Collectivism's Influence on Cross-sectoral Synergy - Based on the Comparison of Chinese and Western Culture, Jiang Minjuan - "Yunnan Social Sciences" - 2016 - Cited: 0

[4] Transcending, Freeing and Surpassing between East and West - Reading New Perspective of Prof. Long Denggao, "Barriers to Crossing the Market: Overseas Chinese Entrepreneurs in the Country, System and Culture" Succeed, Starry Sky - "Historical Studies of Overseas Chinese" $2007-1$

[5] On the cultural differences between China and the West on the impact of intercultural communication, Wu Qing, Li Xiaohong, Zhejiang Institute of Media "Questions and Research: New Curriculum Forum" 2016 12, 123-124. 